\title{
Design and Simulation Analysis of 55kw 12/8 Switched Reluctance Motor for Air Compressor
}

\author{
Hongxia Yang*, Huiqin Sun and Hua Meng \\ Hebei University of Science and Technology, Shijiazhuang, China \\ *Corresponding author
}

\begin{abstract}
The vibration and noise of switched reluctance motor are too large, which becomes an obstacle to the application of switched reluctance motor in air compressor. In this paper, a 55 kw 12/8 switched reluctance motor(SRM) for air compressor was designed, and static simulation analysis was carried out on the basis of finite element analysis software ANSOFTMAXWELL 2D, and the characteristic curve of the motor was obtained. The noise source of the SRM was analyzed, and the radial electromagnetic force was numerically calculated and obtained the air gap is the main structural parameter which affect the vibration of the motor. The air gap was parameterized and and the result provides the basis for optimization of motor parameters.
\end{abstract}

Keywords-air compressor; switched reluctance motor; radial force; parameter analysis; air gap

\section{INTRODUCTION}

Compressors are all kinds of general machinery and equipment, products with the technical progress from the piston compressor, twin screw compressor to today's single screw compressor. At present, the air compressor requires the motor to have high speed, strong starting torque, light weight, high efficiency and low noise [1]. Induction motor has simple structure, easy to manufacture, cheap, easy to operate, but the power factor is lagging behind, light load power factor is low, speed performance slightly worse. SRM is not only efficient, reliable, wide speed range, and excellent start-up, braking characteristics, but the SRM running vibration and noise is too large, which becomes a switched reluctance motor used in air pressure Machine an obstacle. In this paper, presented the use of SRM as a single screw air compressor drive motor, designed a $55 \mathrm{kw}$ 12/8 SRM, and the characteristic curve of the motor is obtained. The noise source of the SRM is analyzed, and the radial electromagnetic force is numerically calculated and extracted to obtain the main structural parameters which affect the vibration of the motor, which provides the basis for the parameters optimization of the motor.

\section{STRUCTURE AND PARAMETERS OF SWITCHED RELUCTANCE MOTOR}

The asynchronous motors, for $37 \mathrm{kw}$ single screw air compressor, rated speed of $2980 \mathrm{rpm}$, displacement $6 \mathrm{~m} 3 / \mathrm{min}$, speed performance is poor, low efficiency. Ideally, if the use of SRM as the drive motor, the same pressure, power up to 55 $\mathrm{kw}$, speed increased to $6000 \mathrm{rpm}$, displacement can reach 12 $\mathrm{m} 3 / \mathrm{min}$, can greatly improve the efficiency of air compressor.
According to the original for the $37 \mathrm{kw}$ air compressor asynchronous motor size and other dimensions, the initial set the motor stator diameter of $327 \mathrm{~mm}$. If the phases number of the SRM is greater, the angular position of the rotor between the two phases is reduced, so that the step angle is reduced, which contributes to the reduction of the torque ripple. But the number of phases is more, the salient pole of rotor and the stator will be more, the structure will become more complex, and the main switching components will increase, so that the cost increase [2]. Therefore, this paper designed a $55 \mathrm{kw}$ three-phase $12 / 8$ pole SRM.

Figure 1 shows the structure of switched reluctance motor model. The main parameters of the motor structure are shown in Table 1.

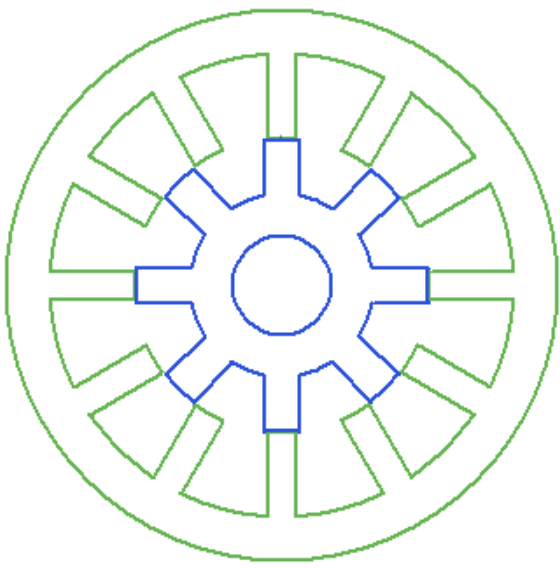

FIGURE I. THREE-PHASE 12 /8 SWITCHED RELUCTANCE MOTOR STRUCTURE 
TABLE I. MAIN PARAMETERS OF THE MOTOR STRUCTURE

\begin{tabular}{|c|c|c|c|}
\hline Name & Data & Name & Data \\
\hline $\begin{array}{c}\text { Number of stator poles } \\
N_{s}\end{array}$ & 12 & $\begin{array}{c}\text { Number of rotor poles } \\
N_{r}\end{array}$ & 8 \\
\hline $\begin{array}{c}\text { Rotor outside diameter } \\
D_{r}(\mathrm{~mm})\end{array}$ & 175 & $\begin{array}{c}\text { Rotor inner diameter } \\
D_{r i}(\mathrm{~mm})\end{array}$ & 60 \\
\hline $\begin{array}{c}\text { Stator outer diameter } \\
D_{s}(\mathrm{~mm})\end{array}$ & 327 & $\begin{array}{c}\text { Stator inner diameter } \\
D_{s i}(\mathrm{~mm})\end{array}$ & 177 \\
\hline $\begin{array}{c}\text { Stator pole arc } \theta_{\mathrm{s} /\left(^{\circ}\right)} \\
\text { Stator yoke height } h_{s} \\
(\mathrm{~mm})\end{array}$ & 26 & $\begin{array}{c}\text { Rotor yoke height } h_{r} \\
(\mathrm{~mm})\end{array}$ & 25 \\
\hline $\begin{array}{c}\text { Air gap } g(\mathrm{~mm}) \\
\text { Core length } l(\mathrm{~mm})\end{array}$ & 1.0 & $\begin{array}{c}\text { Winding turns } T_{p h} \\
\text { (turn) }\end{array}$ & 20 \\
\hline
\end{tabular}

\section{ESTABLISHMENT AND SEGMENTATION OF FINITE ELEMENT MODEL}

Compared with the traditional analytic method and the equivalent magnetic circuit method, the finite element method makes the solution of complex structure and complex boundary problem easy, and can calculate the nonlinear problem of switched reluctance motor [3].

In the ANSOFT software to establish a good motor model, the grid automatically split, split the effect shown in Figure 2 and Figure 3.

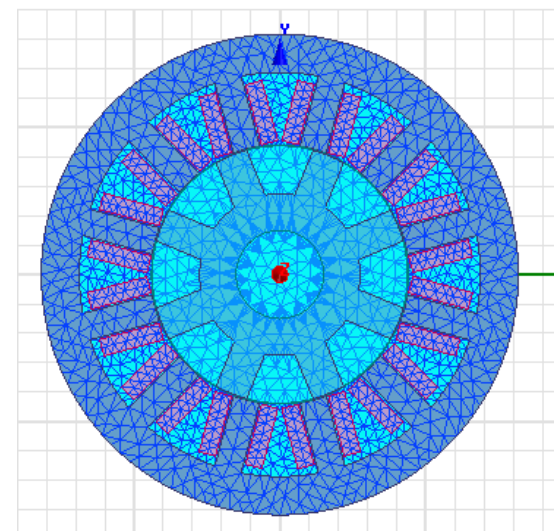

FIGURE II. MOTOR MESH SUBDIVISION

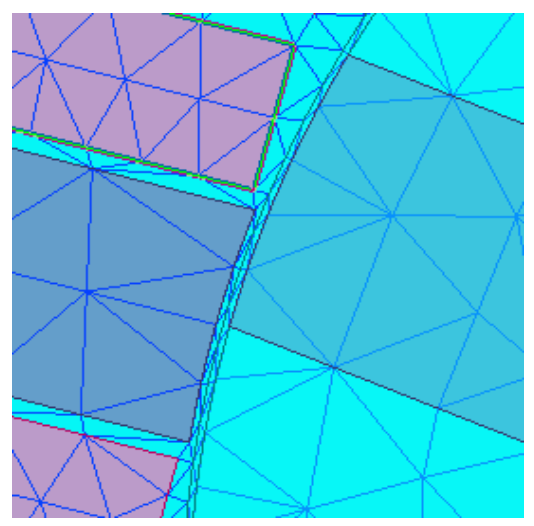

FIGURE III. AIR GAP MAGNIFICATION MESH SUBDIVISION

\section{FinITE ELEMENT SimULATION OF SRM}

The static electromagnetic properties of SRM include flux linkage characteristics, static torque characteristics, and inductive characteristics, which are closely related to motor design and are significant for verifying the correctness and accuracy of motor performance [5].

It can be seen from Figure. 4 that when the rotor pole is close, the air gap is reduced and the magnetic field lines are connected together by the air gap, the rotor body and the stator yoke to form a closed loop. At this time, the magnetic field lines are in a bent state. Figure 5 shows the magnetic field distribution of the motor magnetic field when the single-phase winding is excited. As shown in Figure 6, it can be seen that Magnetic saturation has begun to occur at the portion where the stator and rotor are close to each other.

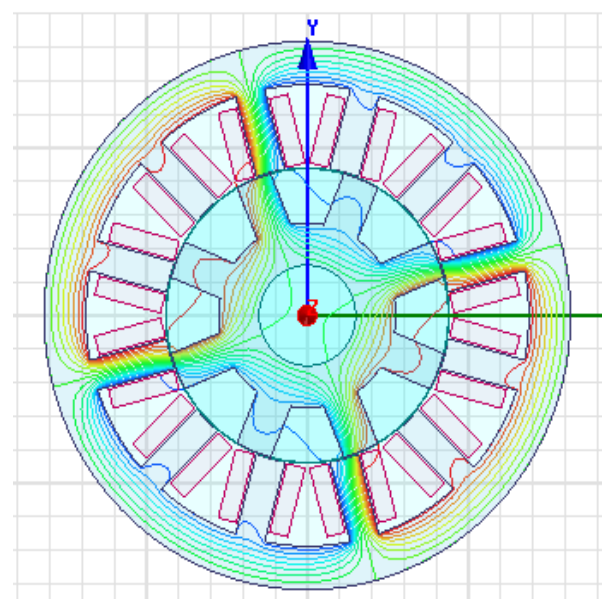

FIGURE IV. FLUX LINES

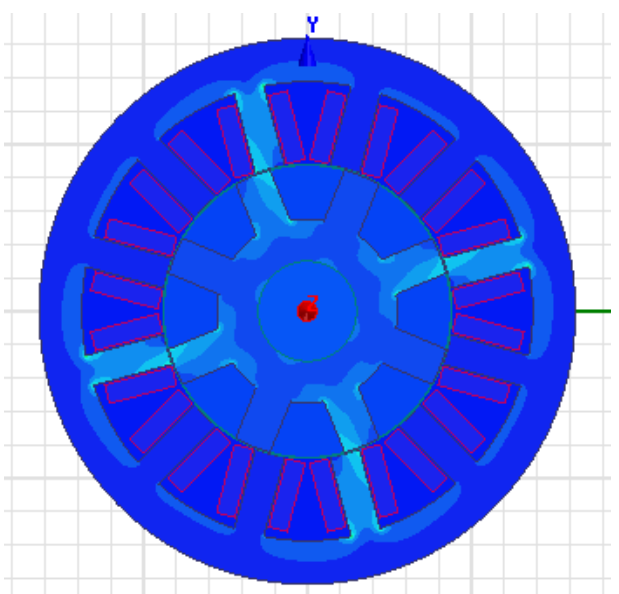

FIGURE V. MAGNETIC DENSITY 


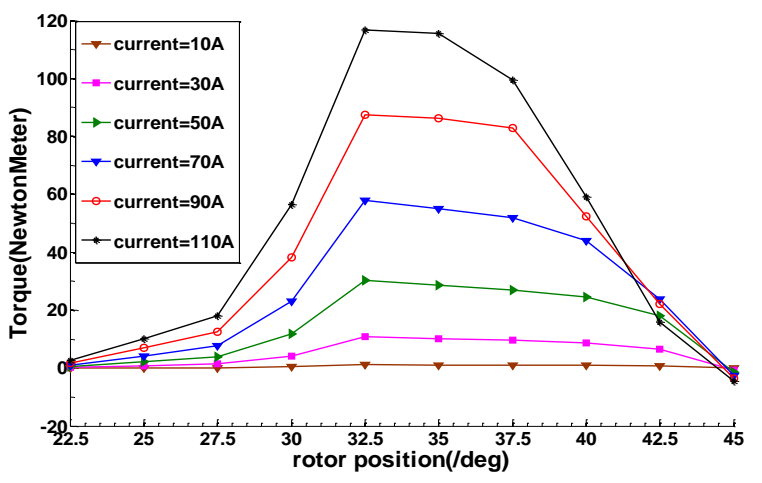

FIGURE VI. TORQUE CHARACTERISTIC CURVE

Figure 6 is the SRM torque characteristic curve. In a half rotor pole distance, conducting the A-phase winding, when the rotor torque in the rotor rotation $22.5^{\circ}$ mechanical angular position, as shown in Figure, the torque is 0 , power generated will pull the rotor by the reluctance torque, when the rotor torque in the rotor rotation $45^{\circ}$ mechanical angular position, the stator and rotor pole completely coincide, when the rotor turns through $45^{\circ}$, and conducting the A-phase winding, the rotor salient pole began to leave the stator salient pole, resulting in negative torque. So the commutation angle must be in the rotor salient pole from the stator salient pole, otherwise the rotor will produce negative torque, reduce the output torque.

\section{PARAMETRIC SIMULATION ANALYSIS}

Electromagnetic noise is the main noise of the switched reluctance motor, the effective suppression of electromagnetic noise can achieve the purpose of motor noise reduction [6]. The electromagnetic noise source from the switched reluctance motor stator, the rotor between the radial pulsating magnetic attraction.

The air gap is the main structural parameter that affects the ratio of radial magnetic force to tangential magnetic force of switched reluctance motor [7]. Based on the virtual displacement method to analyze the electromagnetic force of the switched reluctance motor, the ratio between the radial and tangential magnetic force of the switched reluctance motor is

$$
\delta=\frac{F_{r}}{F_{t}}=-\frac{D_{r} \theta}{g} .
$$

$D_{r}$ is the rotor outside diameter, $\theta_{\text {is the rotor position.It }}$ is concluded from the above formula that the ratio $\delta$ between the radial magnetic force $F_{r}$ and tangential magnetic force $F_{t}$ of the switched reluctance motor is inversely proportional to the size of the air gap g. Reduce $\delta$ to help reduce vibration and noise reduction.

Keep the winding current constant, in a reasonable air gap range: $1.0 \mathrm{~mm}-1.5 \mathrm{~mm}$, air gap length of each increase of 0.1 $\mathrm{mm}$, the stator by the radial magnetic force, the motor output torque calculation.

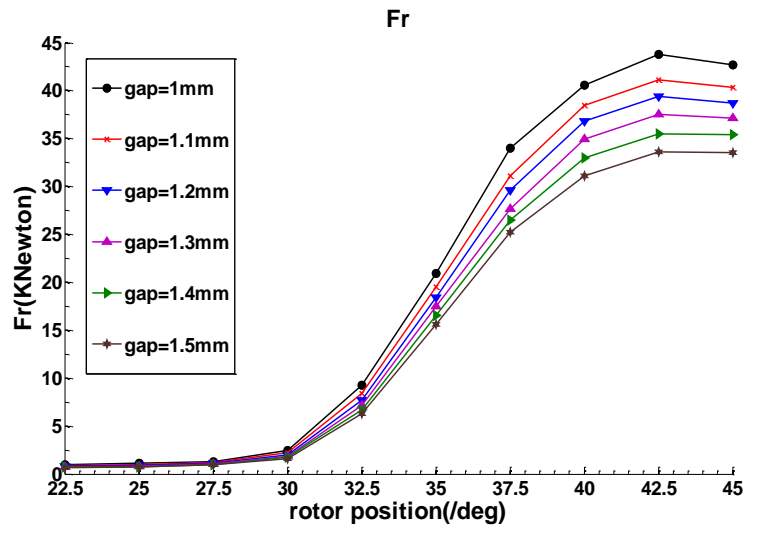

FIGURE VII. RADIAL FORCES VERSUS ROTOR POSITION CURVES OF SINGLE PHASE EXCITED

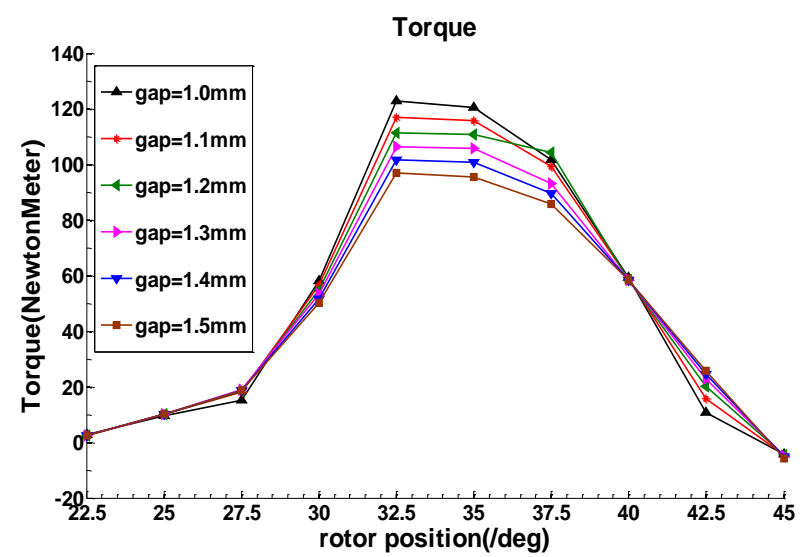

FIGURE VIII. STATIC TORQUE VERSUS ROTOR POSITION CURVES OF SINGLE PHASE EXCITED

Figure 7 for the motor single-phase winding excitation air gap parameterized radial magnetic simulation results, the curve of the abscissa of the rotor position angle $\theta$, from the simulation analysis solution, it can be seen that the radial magnetic force of the motor is very large and can reach the kilo-nanometer scale. From the Figure 8, with the increase of air gap, the radial force is obviously reduced, but it should be noted that the air gap increases, the output torque gradually reduce [8].

In order to reduce noise, air gap size selected $1.2 \mathrm{~mm}$. In contrast, the radial magnetic force was reduced from 41.1 $\mathrm{kN} \cdot \mathrm{m}$ to $34.1 \mathrm{kN} \cdot \mathrm{m}, 15 \%$ lower, and the maximum output torque decreased from $123 \mathrm{~N} \cdot \mathrm{m}$ to $110 \mathrm{~N} \cdot \mathrm{m}$, down by $10.5 \%$. Therefore, for different needs, in the optimization of the motor air gap, should consider the radial force and output torque [9].

\section{CONCLUSION}

(1) A $55 \mathrm{KW}$ air compressor switched reluctance motor was designed. The motor was simulated by ANSOFT MAXWELL2D. The static characteristics of the motor were obtained.

(2) The finite element simulation software is used to simulate the air gap of the motor, and the accurate numerical solution of the change of the torque and the radial force is obtained by gradually changing the air gap size. The air gap parameter can effectively reduce the radial force. 
(3) It is worth noting that the optimized structure reduces the radial force while reducing the average torque, which requires a trade off in the selection of the air gap. Which provides a basis for optimizing the motor parameters by using multi-objective intelligent algorithm.

\section{REFERENCES}

[1] Zheng LF, Xia ZP, Development and Progress of Single Screw Compressor in China. Compressor Technology. 196 (2006) 44-47.

[2] T. J. E. Miller, Optimal design of switched reluctance motors, IEEE Trans. Ind. 49. (2002) 15-27.

[3] Jiang BJ, Zhou L, Zhang DS, Based on External Rotor switched reluctance motor's parameter optimization analysis. Journal of Chongqing jiaotong university. 35 (2016) 174-179.

[4] Zhu ZY, Sun YK, Zhou YH, Electromagnetic analysis and optimization design of single winding bearingless switched reluctance motor. Motor and control applications. 42 (2015) 12-16.

[5] K. Bienkowski, J. Szczypior, B. Bucki, A. Biernat, A. Rogalski, Influence of geometrical parameters of switched reluctance motor on electromagnetic torque, in Proc. XVI Int. Conf. Elect (2014) .

[6] Picod C.,Besbes M.,Camus F.,Gabsi M, Influence of stator geometry upon vibratory behaviour and electromagnetic performances of switched reluctance motors[C]. Electrical Machines and Drives, Eighth International Conference. (1997) 69-73.

[7] Li J, Sun HX, Fan SR, Liu Y, Switched Reluctance Motor's Magnetic Force Analysis and The Drive System Simulation Verification, Proceedings of the 2nd International conference on Industrial and Information Systems. (2010) 210-241.

[8] Cameron D.E., Lang J.H., Umans S.D. The origin of acoustic noise in the switched reluctance motor. Proc. of IEEE IAS Annual Meeting. (1989) 108-115.

[9] Mei JX, Yang ZH, Hu J, SR switch reluctance motor vibration and noise suppression. Shandong Industrial Technology. 174 (2015) 85. 